\title{
Transjugular Portosystemic Stent Shunt: Impact of Right Atrial Pressure on Portal Venous Hemodynamics Within the First Week
}

\author{
Michael Bernhard Pitton ${ }^{1}\left(\mathbb{D} \cdot\right.$ Arndt Weinmann $^{2} \cdot$ Roman Kloeckner $^{1} \cdot$ \\ Jens Mittler ${ }^{3} \cdot$ Christian Ruckes $^{4} \cdot$ Christoph Düber $^{1} \cdot$ Gerd Otto $^{5}$
}

Received: 9 June 2021 / Accepted: 30 October 2021/Published online: 1 December 2021

(C) The Author(s) 2021

\begin{abstract}
Purpose Porto-systemic pressure gradient is used to prognosticate rebleeding and resolution of ascites after TIPS. This study investigates the reliability of portal pressure characteristics as quantified immediately after TIPS placement and at short-term control.

Patients and Methods Portal venous pressure (PVP) and right atrial pressure (RAP) were prospectively obtained before and after TIPS as well as $\geq 48 \mathrm{~h}$ after TIPS procedure. Porto-systemic pressure gradients (PSG) and pressure changes were calculated. A multivariate regression analysis was performed to predict portal hemodynamics at short-term control.

Results The study included 124 consecutive patients. Indications for TIPS were refractory ascites, variceal bleeding or combinations of both. Pre- and post-interventional PSG yielded $16.4 \pm 5.3 \mathrm{mmHg}$ and $5.9 \pm 2.7 \mathrm{mmHg}$, respectively. At that time, 105/124 patients (84.7\%) met the target (PSG $\leq 8 \mathrm{mmHg}$ ). After 4 days (median), PSG was
\end{abstract}

Michael Bernhard Pitton

michael.pitton@unimedizin-mainz.de

1 Department of Diagnostic and Interventional Radiology, University Medical Center, Johannes Gutenberg University Mainz, Langenbeckstr.1, 55131 Mainz, Germany

2 Department of Internal Medicine, University Medical Center, Langenbeckstr.1, 55131 Mainz, Germany

3 Department of General and Visceral Surgery and Transplantation Surgery, University Medical Center, Langenbeckstr.1, 55131 Mainz, Germany

4 Present Address: Interdisciplinary Center for Clinical Trials (IZKS), University Medical Center, 55131 Mainz, Germany

5 Emeritus of the Division of Transplantation Surgery, University Medical Center, Langenbeckstr.1, 55131 Mainz, Germany
$8.5 \pm 3.5 \mathrm{mmHg}$ and only 66 patients (53\%) met that target. In patients exceeding the target PSG at follow-up, PVP was significantly higher and RAP was lower resulting in the increased PSG. The highly variable changes of RAP were the main contributor to different pressure gradients. In the multivariate regression analysis, PVP and RAP immediately after TIPS were predictors for PSG at short-term control with moderately predictive capacity $($ AUC $=0.75)$.

Conclusion Besides the reduction of portal vein pressure, the highly variable right atrial pressure was the main contributor to different pressure gradients. Thus, immediate post-TIPS measurements do not reliably predict portal hemodynamics during follow-up. These findings need to be further investigated with respect to the corresponding clinical course of the patients.

Keywords Liver cirrhosis - Portal hypertension · Transjugular portosystemic stent shunt (TIPS) . Portosystemic pressure gradient (PSG)

\section{Introduction}

Portal hypertension is the crucial pathophysiological finding in end-stage liver cirrhosis and is responsible for clinical complications such as refractory ascites and variceal bleeding [1, 2]. Portal pressure gradients exceeding $10 \mathrm{mmHg}$ are defined as clinically significant portal hypertension [3]. Transjugular Portosystemic Stent Shunt (TIPS) has shown to reduce portal venous pressure (PVP) and porto-systemic pressure gradients (PSG) [4-8] and has been used for risk stratification regarding variceal bleeding and 
refractory ascites $[3,9,10]$. The diameter of the stent shunts is adjusted to pre-defined pressure levels [11, 12] which have to be balanced against hepatic encephalopathy [13].

In clinical practice, we noticed considerable deviations from portal pressure gradients taken immediately after TIPS compared to control measurements after a few days. Patients undergoing TIPS procedures obviously feature varying hemodynamic conditions depending not only on the degree of cirrhosis but also on factors such as preexisting spontaneous porto-venous collaterals, extent of fluid overload, use of diuretics, cardiac pre-conditions and others. The immediate pressure relief after TIPS creation therefore only reflects the instantaneous hemodynamic changes after opening the shunt but does not reflect portal pressure load after equilibration during further follow-up [14]. This study was performed to quantify those timedependent effects on portal hemodynamics and to predict future deviations from the intended PSG at follow-up.

\section{Methods}

\section{Study Population}

Between November 2017 and July 2020, a total of 165 patients were treated with TIPS at our tertiary referral center. Patients with TIPS for porto-mesenterial thrombosis were excluded due to a lack of reliable initial pressure values. Patients who refused short-term follow-up and patients with incomplete pressure protocol were also excluded. Finally, a total of 124 patients with complete pressure measurement, including pre-TIPS and immediate post-TIPS data, and short-term follow-up entered this study (Fig. 1). The study was approved by the local ethics committee (Rhineland Palatinate Ethics Committee, Germany, 15582).

\section{TIPS Technique}

The basic technique for TIPS has been introduced in the 1990s [10] and has been adapted during the years. All TIPS procedures were performed under general anesthesia by two experienced interventional radiologists (MBP, RK). After transjugular approach, the $10 \mathrm{~F}$ sheath was advanced into the inferior vena cava. The right hepatic vein was catheterized and the sheath was advanced into the right hepatic vein. A flexible trocar stylet was advanced until the tip entered the right portal vein (RUPS-100, Cook). TIPS was created via standard access $(n=119)$, left hepatic vein to left portal vein $(n=2)$, middle hepatic vein to right $(n=1)$ and left portal vein $(n=1)$, and direct transcaval to right hepatic vein $(n=1)$.

Pressure measurements were performed using a 5Fpigtail catheter positioned in the main portal vein, whereas

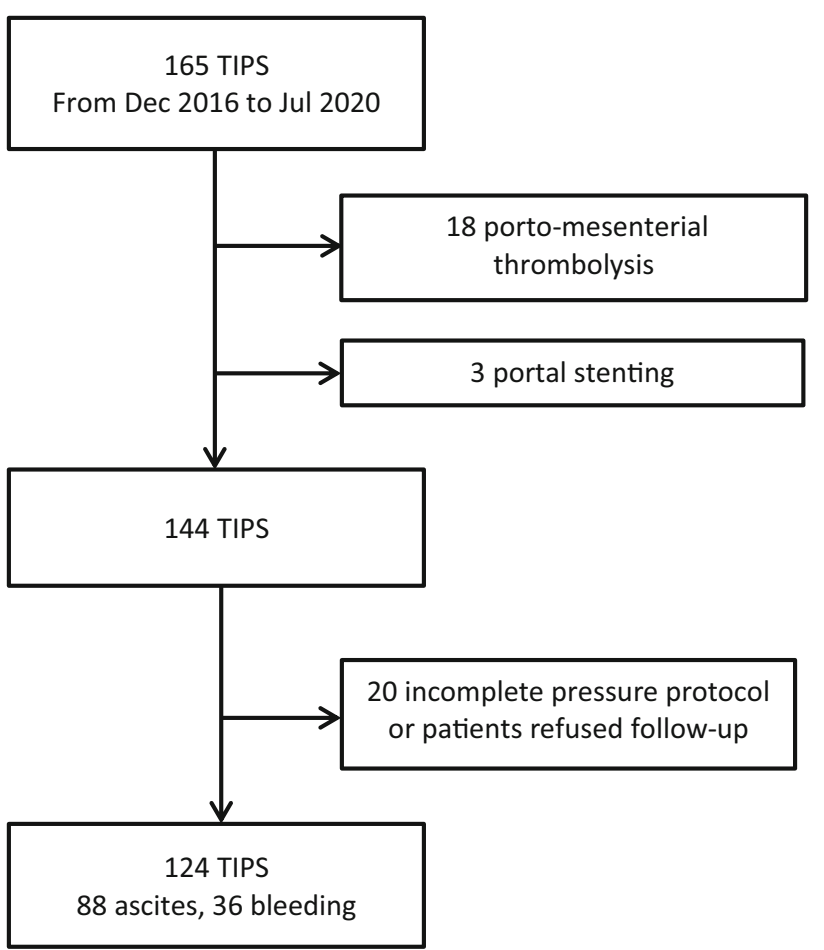

Fig. 1 Flowchart of patient selection

the tip of the $10 \mathrm{~F}$-sheath remained in the right atrium. Mean portal vein pressure (PVP) and mean right atrial pressure (RAP) were registered, and the porto-systemic pressure gradient (PSG) was calculated by the difference of both. Measurements were obtained before (PVPpre, RAPpre) and immediately after TIPS (PVPpost, RAPpost), as well as at short-term follow-up (PVPcontrol, PARcontrol). At these points of time, pressure changes were calculated by subtraction of the respective values, immediately after TIPS ( $\Delta$ post-pre) and at follow-up ( $\Delta$ control-post). All registrations were performed in expiratory arrest, both during general anesthesia pre- and immediately post-TIPS. Measurements at follow-up were obtained without any sedation under controlled expiratory arrest avoiding any Valsalva effects. Measurements were simultaneously obtained with continuous double line registration of PVP and RAP pressure curves using two parallel electromechanical transducers $($ LogiCal $\AA$, Smiths Medical) and a dedicated workstation (Axiom Sensis XP, Siemens). The system was calibrated at the level of the right atrium against the surrounding atmosphere and set to $0 \mathrm{mmHg}$. Pressure registrations were obtained for at least $10 \mathrm{~s}$ to allow for equilibration of the pressure curves of PVP and RAP and to avoid any Valsalva effects.

PTFE-covered stentgrafts were used (Viatorr ${ }^{\circledR}$ and ViatorrCx ${ }^{\circledR}$, Gore) for TIPS. In variceal bleeding, the respective varices and large volume porto-systemic shunts were embolized. The target for post-TIPS PSG was defined 
as $\mathrm{PSG} \leq 8 \mathrm{mmHg}$. In patients with a PSG $>8 \mathrm{mmHg}$ after TIPS, the stentgrafts were adapted by further balloon dilation. In cases in whom this cut-off could not be achieved, no further action was taken at that point. Patients were supervised on the intermediate or intensive care unit and set on heparin according to the underlying co-morbidities and previous coagulation status. Short-term followup was scheduled not before $48 \mathrm{~h}$ after TIPS creation. Patients who fulfilled the cut-off of $\leq 8 \mathrm{mmHg}$ at shortterm follow-up (PSGcontrol) were allocated to group I, and patients who failed this cut-off were allocated to group II.

\section{Statistical Methods}

Statistical calculations were performed using SPSS, version 26 and SAS, Version 9.4. Analysis included descriptive demographic patient data and hemodynamic data before and immediately after TIPS as well as respective hemodynamic data at follow-up. Multivariate regression analysis was performed in order to identify predictors for PSG at short-term follow-up. $P$ values $\leq 0.05$ were considered significant. Based on significant predictors, the sum of the products of the regression coefficients multiplied by the respective individual values was calculated. Receiver operating characteristics (ROC) and areas under the ROC curves (AUROC) were calculated to evaluate the accuracy of risk prediction. Optimal cut-off values for predictors were determined by maximizing the score test statistic.

\section{Results}

A total of 124 patients were included in this prospective register study, 81 male, 43 female, age $58.2 \pm 13.1$ years (Table1). Patients were treated because of refractory ascites ( $n=78)$, variceal bleeding $(n=34)$ or a combination of both $(n=12)$. Before TIPS creation, PVP and RAP were $24.7 \pm 5.2$ and $8.3 \pm 4.6 \mathrm{mmHg}$, respectively, resulting in a PSG of $16.4 \pm 5.3 \mathrm{mmHg}$. After TIPS creation, PVP dropped to $17.6 \pm 4.6 \mathrm{mmHg}$, RAP rose to $11.7 \pm 4.4 \mathrm{mmHg}$ yielding a PSG of $5.9 \pm 2.7 \mathrm{mmHg}$. At short-term follow-up, PVP was further reduced to $15.0 \pm 5.1 \mathrm{mmHg}$ and RAP equilibrated to $6.4 \pm 4.6 \mathrm{mmHg}$ resulting in a respective increase of PSG of $8.5 \pm 3.5 \mathrm{mmHg}$ (Table 2). At this point, patients were allocated in two groups, those who met the target criterion of PSGcontrol $\leq 8 \mathrm{mmHg}$ (group I) and those who did not (group II). The median interval for short-term follow-up was 4 days (detailed data of follow-up intervals are available in Suppl.Tab.1 and 2).

Considering all 124 patients, 105 of 124 patients $(84.7 \%)$ primarily fulfilled the cut-off immediately after TIPS. At follow-up, only 66 patients $(53 \%)$ still met that cut-off (group I), whereas 58 patients (46.8\%) did not (group II, Table 4). The post hoc analysis of pressure data showed that compared to group I, group II presented with significantly higher PVP before and after TIPS, as well as at TIPS control (Table 2). A separate subgroup analysis of those 105 patients who primarily met the cut-off is provided as supplement data. However, there were no discernible relevant differences between the baseline criteria of those patients who subsequently met or did not meet the cut-off PSG at short-term follow-up (Suppl.Tab.3).

Pressure changes during follow-up were significantly different between group I and II. In particular, group II presented with reduced $\triangle \mathrm{PVPcontrol-post}$ and a greater $\triangle$ RAPcontrol-post, resulting in a significantly greater $\triangle$ PSGcontrol-post at follow-up (Table 3, Fig. 2a). The volatility and the greater amounts of changes of the right atrial pressure was the main contributor to the different PSG levels in patients who failed the cut-off at follow-up. At follow-up, PSGcontrol increased in100 patients compared to after TIPS. In 67 of these patients, the increase in PSG was associated with an absolute decrease in PVP and was thus caused by an even greater drop in RAP (Fig. 2b).

If using a different cut-off for PSGcontrol of $\leq 10$ $\mathrm{mmHg}$ or even $\leq 12 \mathrm{mmHg}$, the respective post-TIPS cutoffs were met in 118 and 122 cases, respectively. However, at short-term TIPS control, even these cut-offs were fulfilled in only 94 and 104 cases, respectively (Table 4).

In order to test whether unexpected pressure levels at short-term follow-up would be predictable, all pre- and post-operative pressures (PVP, RAP, PSG) and respective pressure changes were entered into a binary multiple regression analysis. PVPpost and RAPpost after TIPS placement proved to be the best predictors for meeting the targeted PSG at follow-up (PSGcontrol). The ROC analysis yielded only a moderate predictive capacity (AUC = 0.748 ) and sensitivity and specificity of $69.7 \%$ and $75.8 \%$, respectively. Likewise, the AUC values for the follow-up PSG cut-off $\leq 10 \mathrm{mmHg}$ or $\leq 12 \mathrm{mmHg}$ were again only moderately predictive (Table 5, Fig. 3).

\section{Discussion}

This study investigates the changes of portal hemodynamics during short-term follow-up after TIPS creation. Our data show that the PSG obtained immediately after shunt creation does not represent the hemodynamics during further follow-up. Instead, a dynamic equilibration of the pressure values is to be expected resulting in considerable proportion of patients out of the desired pressure range. In particular, the pressure changes of the right atrium were significantly different after TIPS and give an insight into the pathophysiology of different PGS resultants during 
Table 1 Demographics

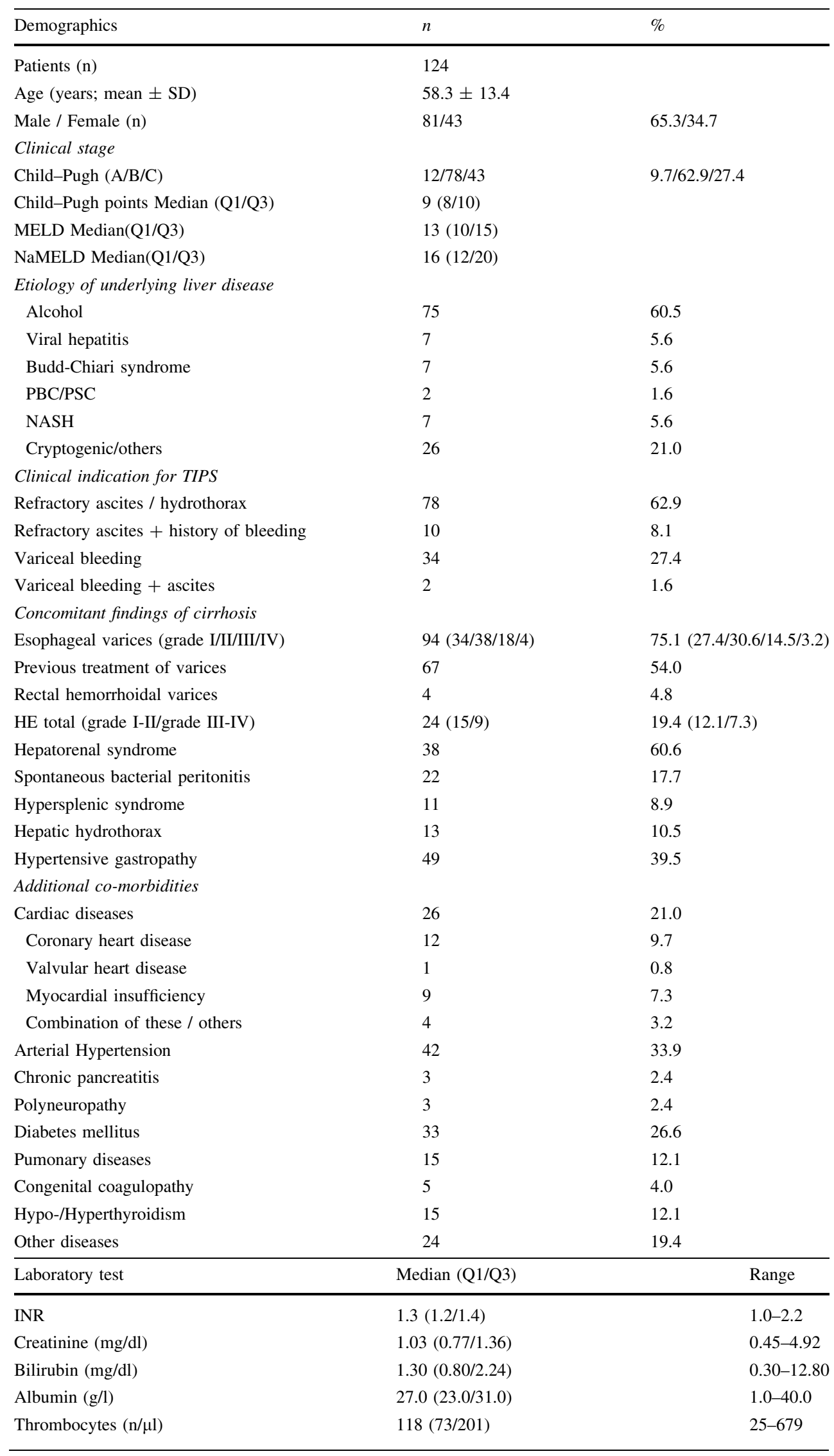


Table 2 Portal hemodynamics before and after TIPS creation. Total: all 124 patients. Group I and II: post hoc allocation of patients to both groups depending on whether patients fulfilled or failed the PSG target at follow-up (PSGcontrol)

\begin{tabular}{llllllllll}
\hline $\begin{array}{l}\text { Portal } \\
\text { Hemodynamics }\end{array}$ & PVPpre & RAPpre & PSGpre & PVPpost & RAPpost & PSGpost & PVPcontrol & RAPcontrol & PSGcontrol \\
\hline Total & $24.7 \pm 5.2$ & $8.3 \pm 4.6$ & $16.4 \pm 5.3$ & $17.6 \pm 4.6$ & $11.7 \pm 4.4$ & $5.9 \pm 2.7$ & $15.0 \pm 5.1$ & $6.4 \pm 4.6$ & $8.5 \pm 3.5$ \\
& $(13$ to 48$)$ & $(-3$ to 27$)$ & $(3$ to 38$)$ & $(6$ to 31$)$ & $(2$ to 26$)$ & $(0$ to 14$)$ & $(3$ to 29$)$ & $(-2$ to 18$)$ & $(1$ to 20$)$ \\
Group I & $23.3 \pm 4.3$ & $7.7 \pm 3.9$ & $15.6 \pm 4.8$ & $16.4 \pm 4.6$ & $11.5 \pm 4.4$ & $4.9 \pm 2.4$ & $13.2 \pm 5.0$ & $7.2 \pm 5.0$ & $6.0 \pm 1.8$ \\
& $(13$ to 33$)$ & $(-3$ to 20$)$ & $(3$ to 31$)$ & $(6$ to 29$)$ & $(2$ to 26$)$ & $(1$ to 14$)$ & $(3$ to 26$)$ & $(0$ to 19$)$ & $(1$ to 8$)$ \\
Group II & $26.3 \pm 5.7$ & $9.1 \pm 5.2$ & $17.2 \pm 5.7$ & $18.9 \pm 4.2$ & $12.0 \pm 4.4$ & $6.9 \pm 2.5$ & $17,0 \pm 4.3$ & $5.6 \pm 3.8$ & $11.5 \pm 2.5$ \\
& $(16$ to 48$)$ & $(0$ to 27$)$ & $(6$ to 38$)$ & $(12$ to 31$)$ & $(4$ to 24$)$ & $(0$ to 13$)$ & $(10$ to 29$)$ & $(-2$ to 16$)$ & $(9$ to 20$)$ \\
$p$ & $<0.01$ & 0.092 & 0.096 & 0.02 & 0.507 & $<0.001$ & $<0.001$ & 0.051 & $<0.001$ \\
\hline
\end{tabular}

Group I, cut-off PSG $<8 \mathrm{mmHg}$ at short-term TIPS control fulfilled; Group II, cut-off PSG failed at short-term TIPS control; $P$, significance level comparing group I and II, T-Test; $P V P$, Portal vein pressure; $R A P$, Right atrial pressure; $P S G$, Porto-systemic pressure gradient; $P V P / R A P /$ PSG pre, pressure levels before TIPS; PVP/RAP/PSGpost, pressure levels immediately after TIPS; PVP/RAP/PSGcontrol, pressure levels at short-term follow-up

Table 3 Individual changes of portal hemodynamics ( $\triangle \mathrm{PVP}, \Delta \mathrm{RAP}, \Delta \mathrm{PSG}) . \Delta$ post-pre, pressure difference between the post-TIPS and preTIPS values. $\Delta$ control-post, pressure difference between TIPS control and immediate post-TIPS values

\begin{tabular}{lllllll}
\hline & $\Delta$ PVPpost-pre & $\Delta$ RAPpost-pre & $\Delta$ PSGpost-pre & $\Delta$ PVPcontrol-post & $\Delta$ RAPcontrol-post & $\Delta$ PSGcontrol-post \\
\hline \multirow{2}{*}{ Group I } & $-6.9 \pm 3.9$ & $3.8 \pm 3.5$ & $-10.7 \pm 4.7$ & $-3.2 \pm 4.7$ & $-4.3 \pm 4.7$ & $1.1 \pm 2.6$ \\
& $(-18$ to 2$)$ & $(-3$ to 21$)$ & $(-28$ to 0$)$ & $(-14$ to 5$)$ & $(-17$ to 6$)$ & $(-8$ to 5$)$ \\
\multirow{2}{*}{ Group II } & $-7.4 \pm 5.1$ & $2.9 \pm 3.8$ & $-10.3 \pm 5.1$ & $-1.9 \pm 4.2$ & $-6.4 \pm 5.0$ & $4.5 \pm 3.2$ \\
& $(-34$ to 2$)$ & $(-8$ to 11$)$ & $(-28$ to 1$)$ & $(-12$ to 9$)$ & $(-21$ to 3$)$ & $(-3$ to 12$)$ \\
$p$ & 0.583 & 0.198 & 0.643 & 0.1 & 0.017 & 0.001
\end{tabular}

Group I, cut-off PSG $<8 \mathrm{mmHg}$ at short-term TIPS control fulfilled; Group II, cut-off PSG failed at short-term TIPS control, $P$, significance level comparing group I and II, T-Test

follow-up. This is of particular interest because the right atrium, the zero point of cardiopulmonary circulation, acts retrograde on portal pressure after TIPS creation. This includes that different portal pressures might result in the same pressure gradient. Vice versa, a particular portal pressure might result in diverse portal pressure gradients.

Silva-Junior et al. have already reported on timing effects of portal pressure gradients after TIPS placement [14]. The authors reported either reduced or even increased immediate pressure gradients depending on whether TIPS was performed under general anesthesia or in deep sedation. Their data were retrospectively collected over 8 years at seven institutions and covered different conditions concerning emergencies versus elective procedures. The major drawback of that publication is, however, the lack of precise data explaining those PSG changes over time. It is of crucial interest to show if changes in PSG are caused by altering PVP or by RAP. In contrast, our data were prospectively collected and are based on simultaneous registration of PVP,
RAP, and PSG as well as individual pressure changes over time. Thereby, the specific cut-off level for the target PSG itself is of minor impact on our general statement that the immediate PSG should not be used for risk prediction or further decision-making regardless of the targeted PSG (8, 10 , or $12 \mathrm{mmHg}$ ). Clinical guidelines with respective recommendations based on a certain PSG immediately measured after TIPS should be questioned.

The pathophysiology of venous return is very complex, particularly in cirrhotic patients. As defined by Guyton, venous return $(\mathrm{VR})$ is the result of the pressure gradient between the mean systemic filling pressure (MSFP) and the right atrial pressure (RAP) divided by the resistance to venous return $(\mathrm{RVR})(\mathrm{VR}=\mathrm{MSFP}-\mathrm{RAP} / \mathrm{RVR})$. According to this equation, venous return increases with high MSFP and low right atrial pressure [15-17]. In a clinical setting, only RAP and not factors such as volume load, elastic distension of the veins, sympathetic tone, cardiac function, drugs etc. can reliably be obtained during a TIPS 


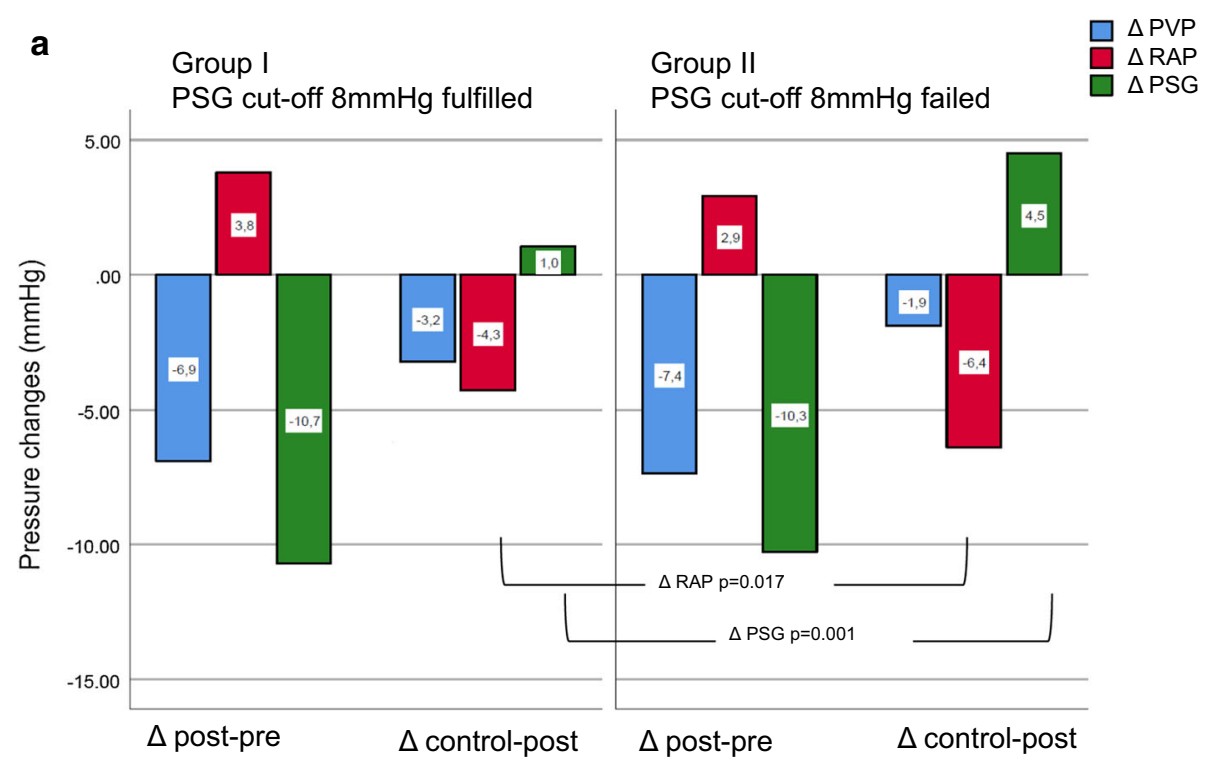

b

$\triangle \mathrm{RAP}$ control-post

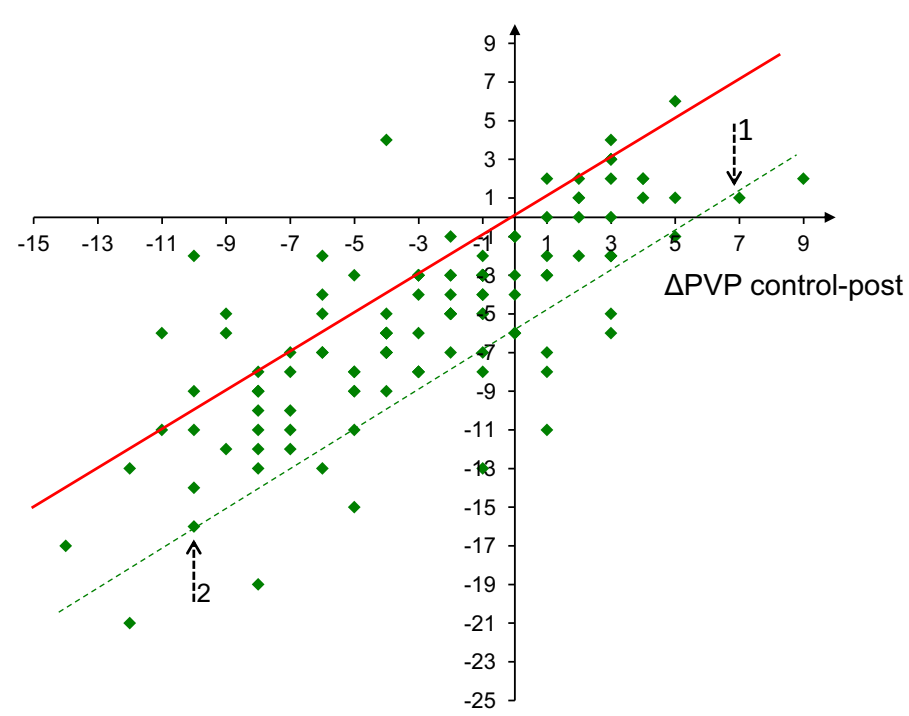

Fig. 2 Pressure changes following TIPS. a $\triangle$ PVPpost-pre (blue), $\triangle$ RAPpost-pre (red), $\triangle$ PSGpost-pre (green): Mean pressure changes immediately after TIPS compared to pre-interventional measurement. $\triangle \mathrm{PVPcontrol-post,} \triangle \mathrm{RAPcontrol-post,} \triangle \mathrm{PSG}$ control-post: Mean pressure changes at short-term follow-up compared to immediate postTIPS measurement. Group I: Cut-off PSG $\leq 8 \mathrm{mmHg}$ at short-term follow-up fulfilled. Group II: Cut-off PSG failed at short-term followup. b Dotplot of the distribution of individual pressure changes at short-term follow-up ( $\triangle$ PVPcontrol-post and $\triangle$ RAPcontrol-post); 4 dots lacking because of identical characteristics at post-TIPS and

procedure. The venous return and the potential backpressure from the right atrium into the liver veins cover a variety of pathophysiological effects that need for equilibration during follow-up and potentially impact the further clinical course. After TIPS placement, the situation is follow-up measurements. Cases localized above the oblique red line had a further decrease in PSG at follow-up compared to immediate post-TIPS measurement with diverse $\triangle \mathrm{PVP}$ and $\triangle \mathrm{RAP}$. Cases on the red line had identical PSG after TIPS and at follow-up but different $\triangle \mathrm{PVP}$ and $\triangle \mathrm{RAP}$. Cases below the red line had a further increase of PSG at follow-up compared to immediate post-TIPS. Two examples (green dotted line): Example 1: $\Delta \mathrm{PVP}+7 \mathrm{mmHg}, \Delta \mathrm{RAP}+1$ $\mathrm{mmHg}=\Delta \mathrm{PSG}+6 \mathrm{mmHg}$ compared to PSG after TIPS. Example 2: $\Delta$ PVP $-10 \mathrm{mmHg}, \Delta \mathrm{RAP}-16 \mathrm{mmHg}=\Delta \mathrm{PSG}+6 \mathrm{mmHg}$ compared to PSG after TIPS despite an absolute reduction of PVP

characterized by the reduced porto-venous pressure gradient entailing increased thoracic blood volume and reduced splanchnic blood volume, increasing right atrial and pulmonary artery pressure, as well as respective changes of pulmonary vascular resistance. Systemic vascular 
Table 4 a Number of patients who met the cut-off of PSG $\leq 8 \mathrm{mmHg}$ (Group I) or failed the cut-off (Group II) at short-term follow-up (PSGcontrol). b Number of patients who met or failed the cut-off of PSG $\leq 10 \mathrm{mmHg}$ c Number of patients who met or failed the cut-off of $\mathrm{PSG} \leq 12 \mathrm{mmHg}$

\begin{tabular}{|c|c|c|c|}
\hline & $\begin{array}{l}\text { PSGcontrol } \leq 8 \mathrm{mmHg} \\
\text { Group I }\end{array}$ & $\begin{array}{l}\text { PSGcontrol }>8 \mathrm{mmHg} \\
\text { Group II }\end{array}$ & \\
\hline \multicolumn{4}{|l|}{ (a) } \\
\hline PSGpost $\leq 8 \mathrm{mmHg}$ & 60 & 45 & $\begin{array}{l}105 \\
(84.7 \%)\end{array}$ \\
\hline \multirow[t]{3}{*}{ PSGpost $>8 \mathrm{mmHg}$} & 6 & 13 & 19 \\
\hline & $66(53 \%)$ & $58(46.8 \%)$ & $\begin{array}{l}124 \\
(100 \%)\end{array}$ \\
\hline & PSGcontrol $\leq 10 \mathrm{mmHg}$ & \multicolumn{2}{|l|}{ PSGcontrol > $10 \mathrm{mmHg}$} \\
\hline \multicolumn{4}{|l|}{ (b) } \\
\hline PSGpost $\leq 10 \mathrm{mmHg}$ & 91 & 27 & $118(95.2 \%)$ \\
\hline \multirow[t]{3}{*}{ PSGpost > $10 \mathrm{mmHg}$} & 3 & 3 & $6(4.8 \%)$ \\
\hline & $94(75.8 \%)$ & $30(24.2 \%)$ & $124(10 \%)$ \\
\hline & PSGcontrol $\leq 12 \mathrm{mmHg}$ & \multicolumn{2}{|l|}{ PSGcontrol > $12 \mathrm{mmHg}$} \\
\hline \multicolumn{4}{|l|}{ (c) } \\
\hline PSGpost $\leq 12 \mathrm{mmHg}$ & 102 & 20 & $122(98.4 \%)$ \\
\hline \multirow[t]{2}{*}{ PSGpost $>12 \mathrm{mmHg}$} & 2 & 0 & $2(1.6 \%)$ \\
\hline & $104(83.9 \%)$ & $20(16.1 \%)$ & $124(100 \%)$ \\
\hline
\end{tabular}

PSGpost, PSG immediately after TIPS; PSGcontrol, PSG at short-term follow-up

Table 5 ROC analysis of the risk factors and calculation of AUC for the target PSG at short-term follow-up (PSGcontrol)

\begin{tabular}{llllllll}
\hline & AUC & Intercept & $\begin{array}{l}\text { PVPpost } \\
\text { coefficient }\end{array}$ & $\begin{array}{l}\text { RAPpost } \\
\text { coefficient }\end{array}$ & $\begin{array}{l}\text { Optimal } \\
\text { cut-off }\end{array}$ & Sensitivity & Specificity \\
\hline PSGcontrol $\leq 8 \mathrm{mmHg}$ & 0.748 & 3.3947 & -0.3769 & 0.2879 & -3.1511 & $69.7 \%$ & $75.8 \%$ \\
PSGcontrol $\leq 10 \mathrm{mmHg}$ & 0.766 & 4.8949 & -0.3549 & 0.2297 & -3.9240 & $76.6 \%$ & $70.0 \%$ \\
PSGcontrol $\leq 12 \mathrm{mmHg}$ & 0.757 & 4.9863 & -0.3044 & 0.1907 & -3.1135 & $59.6 \%$ & $90.0 \%$ \\
\hline
\end{tabular}

PVPpost, portal venous pressure, immediately after TIPS; RAPpost, right atrial pressure, immediately after TIPS

resistance decreases and renal function improves by increased central blood volume, decreased renal vasoconstriction, decreased activation of the sympathetic nervous system and renin-angiotensin-aldosterone system [18, 19]. In this study, a reliable prediction which patients will experience an increase in PSG was not possible. We therefore suggest short-term follow-up within the first week after TIPS after equilibration of portal hemodynamics.

The hepatic venous pressure gradient (HVPG) as used by the American Association for the Study of the Liver [20] is defined as difference between the pressure of the wedged hepatic vein and the free hepatic vein and is an indirect calculation of pressure gradients rather than a direct measurement [21]. Those HVPG levels have been discussed in clinical studies in order to find adequate cutoff levels ( $\leq 10, \leq 12$, or $\leq 20 \mathrm{mmHg}$ ) with respect to clinical outcome [20, 22-26]. However, these indirect pressure levels might not be compared with directly registered PSG values because of the different technical methods. This is particularly true for a TIPS cohort in whom vascular anatomy has been changed by creation of shunt flow. Furthermore, there have been concerns on whether to obtain the reference measurement from the right atrium, the hepatic veins, from a certain positions within an particular hepatic vein, or, alternatively, from the inferior vena cava as results may be different [27, 28]. In order to cover all these individual confounders, mean right atrial pressure was used as reference pressure in this study. 

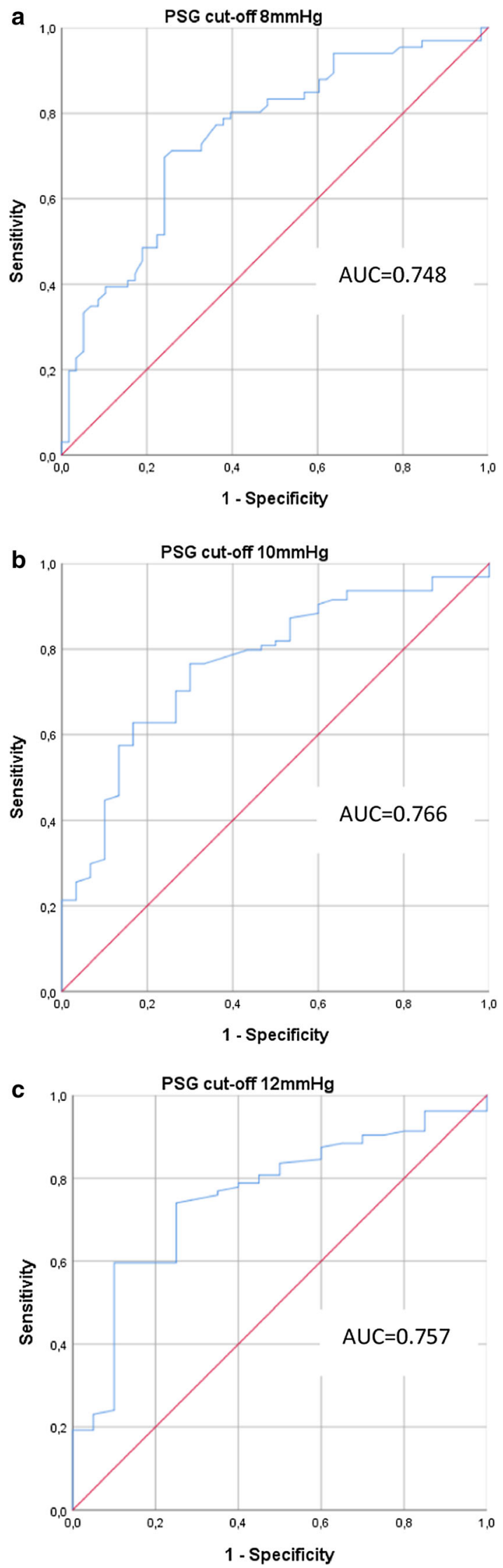

4Fig. 3 ROC analysis of the risk factors and calculation of AUC for the target PSG at short-term follow-up. Results for PSGcontrol $\leq 8 \mathrm{mmHg}$ (Fig. 3a), PSGcontrol $\leq 10 \mathrm{mmHg}$ (Fig. 3b), and PSGcontrol $\leq 12 \mathrm{mmHg}$ (Fig. 3c)

Positioning the tip of the sheath in the right atrium and the catheter within the main portal vein is easy to perform and allows for standardized simultaneous pressure measurements before and after TIPS. In addition, factors like deep sedation, patient movement, and coughing or breathing during measurement may impact pressure levels [29-31]. These factors were overcome by standardized conditions as described above.

PSG, as defined here, is impacted by the whole vascular resistance between the portal vein and the right atrium and includes potential factors such as pre-sinusoidal pathologies, intrahepatic veno-venous shunts, or stenoses of the hepatic and caval vein [21, 23]. Finally, the PSG is affected by the compliance of the right atrium, increased atrial pressures, particularly in heart and pulmonary diseases which cause backpressure for venous return [15-17]. In this study, our suggested PSG cut-off of $\leq 8 \mathrm{mmHg}$ at follow-up is challenging; therefore, the data had also been analyzed for a PSG cut-off of $\leq 10$ and $\leq 12 \mathrm{mmHg}$. However, looking at reports on TIPS using PTFE stentgrafts, the immediate post-TIPS pressure gradients are often between PSG 7 and $9 \mathrm{mmHg}$, independent of the formally defined cut-off level of $<12 \mathrm{mmHg}$ in the respective methods Sects. [32-34]. Insofar, the cut-off defined in our study ( $\mathrm{PSG} \leq 8 \mathrm{mmHg}$ ) is more an adaption to clinical practice.

Our study may be criticized as pathophysiological pressure data follow-up was not correlated with clinical data. Since clinical complications such as rebleeding and alleviation of ascites have been reported to correlate with PSG, we herein focused on this issue to point out the changes of porto-venous features and not the clinical sequelae. Another point of criticism may be that secondary alterations of the TIPS tract impacting shunt flow or remodeling of the TIPS tract by curving, kinking, and radial forces of the stent which may take longer than 4 days $[35,36]$. Finally and most important, clinical outcome is influenced by the entity and progression of the underlying diseases, which was also beyond the scope of this study. Further studies should therefore investigate the portal hemodynamics and correlate with clinical outcome and reintervention rates during mid-term and long-term followup.

In conclusion, pressure characteristics significantly changes within a few days after TIPS placement. Data obtained immediately after the TIPS procedure have only moderate predictive power for the future portal 
hemodynamics. Besides the absolute pressure reduction in the portal vein, the highly variable right atrial pressure changes were the main contributor to different pressure gradients. This includes the possibility that different portal vein pressures may result in the same pressure gradients and vice versa. Since pressure gradients have been reported to impact further clinical proceeding, studies are required to correlate detailed hemodynamic changes with clinical outcome.

Funding Open Access funding enabled and organized by Projekt DEAL. This study was not supported by any funding.

\section{Declarations}

Conflict of interest The authors declare that they have no conflict of interest.

Ethical Approval For this type of study, formal consent is not required, approved by the local ethic committee (Rhineland Palatinate Ethics Committee, Germany).

Informed Consent For this type of study, informed consent is not required.

Consent for Publication For this type of study, consent for publication is not required.

Supplementary Information The online version contains supplementary material available at https://doi.org/10.1007/s00270021-03003-z.

Open Access This article is licensed under a Creative Commons Attribution 4.0 International License, which permits use, sharing, adaptation, distribution and reproduction in any medium or format, as long as you give appropriate credit to the original author(s) and the source, provide a link to the Creative Commons licence, and indicate if changes were made. The images or other third party material in this article are included in the article's Creative Commons licence, unless indicated otherwise in a credit line to the material. If material is not included in the article's Creative Commons licence and your intended use is not permitted by statutory regulation or exceeds the permitted use, you will need to obtain permission directly from the copyright holder. To view a copy of this licence, visit http://creativecommons. org/licenses/by/4.0/.

\section{References}

1. Tsochatzis EA, Bosch J, Burroughs AK. Liver cirrhosis. Lancet. 2014;383(9930):1749-61.

2. EASL. EASL clinical parctice guidelines on the management of ascites, spontaneous bacterial peritonitis, and hepatorenals syndrome in cirrhosis. Journal of hepatology. 2010;53(53):397-417.

3. de Franchis R, Baveno VIF. Expanding consensus in portal hypertension: Report of the Baveno VI Consensus Workshop: Stratifying risk and individualizing care for portal hypertension. J Hepatol. 2015;63(3):743-52.

4. Lee EW, Kuei A, Saab S, Busuttil RW, Durazo F, Han SH, et al. Nationwide trends and predictors of inpatient mortality in 83884 transjugular intrahepatic portosystemic shunt. World J Gastroenterol. 2016;22(25):5780-9.

5. Bercu ZL, Fischman AM. Outcomes of transjugular intrahepatic portosystemic shunts for ascites. Semin Interv Radiol. 2014;31(3):248-51.

6. Garcia-Pagan JC, Caca K, Bureau C, Laleman W, Appenrodt B, Luca A, et al. Early use of TIPS in patients with cirrhosis and variceal bleeding. N Engl J Med. 2010;362(25):2370-9.

7. Li GQ, Yang B, Liu J, Wang GC, Yuan HP, Zhao JR, et al. Hepatic venous pressure gradient is a useful predictor in guiding treatment on prevention of variceal rebleeding in cirrhosis. Int $\mathbf{J}$ Clin Exp Med. 2015;8(10):19709-16.

8. Qi XS, Fan DM. Hepatic venous pressure gradient measurement before TIPS for acute variceal bleeding. World J Gastroenterol. 2014;20(23):7523-4.

9. Garcia-Tsao G. Current Management of the Complications of Cirrhosis and Portal Hypertension: Variceal Hemorrhage, Ascites, and Spontaneous Bacterial Peritonitis. Dig Dis. 2016;34(4):382-6.

10. Rossle M, Haag K, Ochs A, Sellinger M, Noldge G, Perarnau JM, et al. The transjugular intrahepatic portosystemic stent-shunt procedure for variceal bleeding. $N$ Engl $\mathrm{J}$ Med. 1994;330(3):165-71.

11. Geeroms B, Laleman W, Laenen A, Heye S, Verslype C, van der Merwe S, et al. Expanded polytetrafluoroethylene-covered stentgrafts for transjugular intrahepatic portosystemic shunts in cirrhotic patients: Long-term patency and clinical outcome results. Eur Radiol. 2017;27(5):1795-803.

12. Miraglia R, Maruzzelli L, Di Piazza A, Mamone G, Caruso S, Gentile G, et al. Transjugular Intrahepatic Portosystemic Shunt Using the New Gore Viatorr Controlled Expansion Endoprosthesis: Prospective, Single-Center. Preliminary Experience Cardiovasc Intervent Radiol. 2019;42(1):78-86.

13. Rowley MW, Choi M, Chen S, Hirsch K, Seetharam AB. Refractory Hepatic Encephalopathy After Elective Transjugular Intrahepatic Portosystemic Shunt: Risk Factors and Outcomes with Revision. Cardiovasc Intervent Radiol. 2018;41(110):1765-72.

14. Silva-Junior G, Turon F, Baiges A, Cerda E, Garcia-Criado A, Blasi A, et al. Timing Affects Measurement of Portal Pressure Gradient After Placement of Transjugular Intrahepatic Portosystemic Shunts in Patients With Portal Hypertension. Gastroenterology. 2017; 152(6):1358-65.

15. Guyton AC, Lindsey AW, Abernathy B, Richardson T. Venous return at various right atrial pressures and the normal venous return curve. Am J Physiol. 1957;189(3):609-15.

16. Guyton AC. Physiology of heart failure. Trans Am Coll Cardiol. 1957;7:214-24.

17. Moller PW, Winkler B, Hurni S, Heinisch PP, Bloch A, Sondergaard S, et al. Right atrial pressure and venous return during cardiopulmonary bypass. Am J Physiol Heart Circ Physiol. 2017;313(2):H408-20.

18. Busk TM, Bendtsen F, Henriksen JH, Fuglsang S, Clemmesen JO, Larsen FS, et al. Effects of transjugular intrahepatic portosystemic shunt (TIPS) on blood volume distribution in patients with cirrhosis. Digestive Liver Dis. 2017;49(12):1353-9.

19. Busk TM, Bendtsen F, Poulsen JH, Clemmesen JO, Larsen FS, Goetze JP, et al. Transjugular intrahepatic portosystemic shunt: impact on systemic hemodynamics and renal and cardiac function in patients with cirrhosis. Am J Physiol Gastrointest Liver Physiol. 2018;314(2):G275-86.

20. Garcia-Tsao G, Abraldes JG, Berzigotti A, Bosch J. Portal hypertensive bleeding in cirrhosis: Risk stratification, diagnosis, and management: 2016 practice guidance by the American 
Association for the study of liver diseases. Hepatology. 2017;65(1):310-35.

21. Kibrit J, Khan R, Jung BH, Koppe S. Clinical Assessment and Management of Portal Hypertension. Semin Interv Radiol. 2018;35(3):153-9.

22. Kim TY, Lee JG, Sohn JH, Kim JY, Kim SM, Kim J, et al. Hepatic Venous Pressure Gradient Predicts Long-Term Mortality in Patients with Decompensated Cirrhosis. Yonsei Med J. 2016;57(1):138-45.

23. Tey TT, Gogna A, Irani FG, Too CW, Lo HG, Tan BS, et al. Application of a standardised protocol for hepatic venous pressure gradient measurement improves quality of readings and facilitates reduction of variceal bleeding in cirrhotics. Singapore Med J. 2016;57(3):132-7.

24. Lee JG, Sohn JH, Jeong JY, Kim TY, Kim SM, Cho YS, et al. Combined effect of hepatic venous pressure gradient and liver stiffness on long-term mortality in patients with cirrhosis. Korean J Intern Med. 2020;35(1):88-98.

25. Liu C, Liu Y, Shao R, Wang S, Wang G, Wang L, et al. The predictive value of baseline hepatic venous pressure gradient for variceal rebleeding in cirrhotic patients receiving secondary prevention. Ann Transl Med. 2020;8(4):91.

26. Maruyama H, Kobayashi K, Kiyono S, Ogasawara S, Ooka Y, Suzuki E, et al. Incidence and hemodynamic feature of risky esophageal varices with lower hepatic venous pressure gradient. Int J Med Sci. 2019;16(12):1614-20.

27. La Mura V, Abraldes JG, Berzigotti A, Erice E, Flores-Arroyo A, Garcia-Pagan JC, et al. Right atrial pressure is not adequate to calculate portal pressure gradient in cirrhosis: a clinical-hemodynamic correlation study. Hepatology. 2010;51(6):2108-16.

28. Rossle M, Blanke P, Fritz B, Schultheiss M, Bettinger D. Free Hepatic Vein Pressure Is Not Useful to Calculate the Portal Pressure Gradient in Cirrhosis: A Morphologic and Hemodynamic Study. J Vasc Interventional Radiol. 2016;27(8):1130-7.

29. Steinlauf AF, Garcia-Tsao G, Zakko MF, Dickey K, Gupta T, Groszmann RJ. Low-dose midazolam sedation: an option for patients undergoing serial hepatic venous pressure measurements. Hepatology. 1999;29(4):1070-3.
30. Reverter E, Blasi A, Abraldes JG, Martinez-Palli G, Seijo S, Turon F, et al. Impact of deep sedation on the accuracy of hepatic and portal venous pressure measurements in patients with cirrhosis. Liver Int. 2014;34(1):16-25.

31. Tandon P, Ripoll C, Assis D, Wongcharatrawee S, Groszmann RJ, Garcia-Tsao G. The interpretation of hepatic venous pressure gradient tracings - excellent interobserver agreement unrelated to experience. Liver Int. 2016;36(8):1160-6.

32. Miraglia R, Maruzzelli L, Tuzzolino F, Petridis I, D’Amico M, Luca A. Transjugular Intrahepatic Portosystemic Shunts in Patients with Cirrhosis with Refractory Ascites: Comparison of Clinical Outcomes by Using 8- and 10-mm PTFE-covered Stents. Radiology. 2017;284(1):281-8.

33. Masson S, Mardini HA, Rose JD, Record CO. Hepatic encephalopathy after transjugular intrahepatic portosystemic shunt insertion: a decade of experience. QJM. 2008;101(6):493-501.

34. Lv Y, Qi X, He C, Wang Z, Yin Z, Niu J, et al. Covered TIPS versus endoscopic band ligation plus propranolol for the prevention of variceal rebleeding in cirrhotic patients with portal vein thrombosis: a randomised controlled trial. Gut. 2018;67(12):2156-68.

35. Sauerbruch T, Mengel M, Dollinger M, Zipprich A, Rossle M, Panther E, et al. Prevention of Rebleeding From Esophageal Varices in Patients With Cirrhosis Receiving Small-Diameter Stents Versus Hemodynamically Controlled Medical Therapy. Gastroenterology. 2015;149(3):660-8.

36. Pieper CC, Sprinkart AM, Nadal J, Hippe V, Meyer C, Schild $\mathrm{HH}$, et al. Postinterventional passive expansion of partially dilated transjugular intrahepatic portosystemic shunt stents. J Vasc Interventional Radiol. 2015;26(3):388-94.

Publisher's Note Springer Nature remains neutral with regard to jurisdictional claims in published maps and institutional affiliations. 